\title{
Um Gilberto Freyre à francesa: recepçã̃o, ensaísmo e circulação internacional
}

Gilberto Freyre à la Française: Reception, Essayism and International Circulation

Alberto Luiz Schneider*

VENANCIO, Giselle Martins; FURTADO, André. Mestiça cientificidade: três leitores franceses de Gilberto Freyre e a sua máxima consagração no exterior. Niterói: Eduff, 2020. 136 p.

A Editora da Universidade Federal Fluminense acaba de lançar Mestiça cientificidade: três leitores franceses de Gilberto Freyre e a sua máxima consagração no exterior (2020). O livro de Giselle Martins Venancio e André Furtado é uma importante contribuição para interpretar a recepção da obra de Gilberto Freyre no exterior, em especial na França do pós-guerra. Compreender as condições de leitura de autores canônicos como Fernand Braudel, Roger Bastide e Lucien Febvre - os leitores franceses estudados no livro - não é trivial, pois a consagração de Casa-grande \& Senzala (1933), de Gilberto Freyre (1900-1987), não dependeu apenas do próprio texto, nem da argumentação e da pesquisa contidas nele, mas de uma série de questões que povoam o mundo dos leitores.

Mestiça cientificidade aprofunda o entendimento acerca da recepção francesa de Casa-grande nas décadas de 1940 e 1950. Funciona também como iniciação à obra de Gilberto Freyre para estudantes, jovens pesquisadores e interessados em um dos autores brasileiros mais importantes do século XX, o de maior repercussão internacional, objeto ainda hoje de acalorado debate público. Sem perder a potência da pesquisa e dos debates acadêmicos contemporâneos, o livro em questão não deixa de praticar história pública.

A recepção francesa de Casa-grande - ou, mais especificamente, a leitura que Fernand Braudel, Roger Bastide e Lucien Febvre empreenderam - só pode ser compreendida nos limites do pós-guerra, que marcaram o apogeu da reputação internacional de Freyre. Em 1946 é publicada a tradução norte-america-

\footnotetext{
* Pontifícia Universidade Católica de São Paulo (PUC-SP), São Paulo, SP, Brasil. alschneider@pucsp.br $<$ https://orcid.org/0000-0002-7308-2524>
} 
na de Casa-grande pela editora Alfred Knopf, com tradução de Samuel Putman. Logo em seguida, em 1947, sai a edição britânica.

Em 1948, a Unesco organiza um encontro para debater a questão racial, em que o Brasil - lido com tintas freyrianas, diga-se - aparece como modelo promissor de convivência interracial. A Unesco reuniu intelectuais europeus e norte-americanos e o próprio Gilberto Freyre, o único intelectual latino-americano presente no evento, o que demonstra o seu prestígio. O projeto da Unesco visava combater a mentalidade nacionalista, racista e segregacionista, em defesa da liberdade, da democracia e do combate ao racismo.

Em 1952 veio a público Maîtres et Esclaves, a tradução francesa de Casa-grande \& Senzala, feita justamente por Roger Bastide, sociólogo que viveu no Brasil como professor da Universidade de São Paulo. O livro de Freyre saiu dentro da Coleção La Croix du Sud, dirigida por Roger Caillois, pela Gallimard, uma casa editorial que assumia certa vocação internacionalista, bem ajustada aos ventos democratizantes do pós-guerra. Convém observar que, além do latino-americanismo francês, interessava a "proposta otimista" na compreensão do outro contida na obra de Freyre.

Os três leitores franceses de Gilberto Freyre já conheciam a obra do intelectual pernambucano antes do fim da guerra. Não há dúvida que a experiência trágica do nazismo e da Segunda Guerra marcam a leitura da obra de Freyre e a própria percepção do Brasil. Lembremos que Braudel e Bastide tinham uma vantagem extra: conheciam e eram apresentados como franceses profundamente familiarizados com o Brasil, pois haviam vivido no país, o que aumentava-lhes a credibilidade como leitores aparelhados de Freyre, autor que gozava da reputação antirracista, que havia escrito em favor da mestiçagem no exato momento que o nazismo e o apartheid foram erigidos. A simpatia a Freyre no pós-guerra é compreensível, demonstram os autores:

[...] nesse momento, a máxima credibilidade intelectual de Gilberto Freyre na década de 1950 também era impulsionada pela visibilidade que países como o Brasil ganhavam na cena internacional em termos políticos, econômicos e culturais. Essa tensão correspondia ao olhar europeu que se voltava para o Sul global como se procurasse um oásis que subtraísse o passado recente. Abaixo da Linha do Equador estavam as terras prósperas, e via de regra, convivendo em paz. Era esse o tempo perdido que a Europa buscava restaurar, apontando Casa-grande \& senzala como exemplar testemunho do histórico encontro de civilizações ao qual, à época, supunha-se incruento e harmonioso (Venancio; Furtado, 2020, p. 41). 
Não há qualquer dúvida que a questão racial marcou a interpretação que os intelectuais franceses fizeram de Casa-grande. No pós-guerra, o tema do racismo - potencializado pela descolonização da África e pelo movimento negro norte-americano - estava definitivamente na ordem do dia. Nas décadas de 1950 e início de 1960, o discurso racial freyriano claramente havia envelhecido. O livro do historiador inglês Charles Boxer - Race Relations in the Portuguese Colonial Empire, 1415-1825, publicado em 1963 (Boxer, 1963; 1967) -, fruto de conferências proferidas na Universidade da Virgínia, nos Estados Unidos, em 1962, evidencia o quanto esse discurso, reconfigurado pelo lusotropicalismo, soava cada vez menos contemporâneo ante à evidente politização da raça, já desde os anos 50 .

Vivia-se uma profunda politização da questão racial no pensamento intelectual, como sugerem as obras de crítica ao colonialismo, a exemplo de Frantz Fanon, autor de Peau noire, masques blancs (1952) e, mais tarde, Les Damnés de la Terre (1961), ou ainda dos livros de Aimée Cesaire, autor de Discours sur le colonialisme (1950). Nota-se ainda a influência da antropologia francesa, em que se destaca Claude Lévi-Strauss, que também havia vivido no Brasil, o qual publica Race et histoire (1952) e Tristes tropiques (1955). Ainda na França, naquele mesmo período, encontra-se a obra de Michel Leiris Race et civilisation (1951).

Enfim, naqueles anos, a crítica ao racismo e ao colonialismo se consolidavam, cada vez mais hostis às noções de superioridade ocidental. De uma maneira ou de outra, essas questões aparecem na leitura de Fernand Braudel, Roger Bastide e Lucien Febvre. No entanto, Gisele Venancio e André Furtado, em Mestiça cientificidade, optaram por debater outra questão: o ensaio como gênero, num tempo em que, no Brasil, as ciências sociais se profissionalizavam, especialmente na Faculdade de Filosofia da USP, com Florestan Fernandes e seu grupo ainda fortemente marcados pela cientificidade herdada da Escola de Sociologia de Chicago, de nomes como Robert Park ou Robert Redfield, entre outros.

Se a leitura racial de Freyre envelhecia, o ensaio interdisciplinar como um modo de pensar as ciências sociais, em tudo oposto ao cientificismo academicista, mantinha surpreendente frescor. É Roger Bastide quem afirma que Freyre havia superado a "tentação matemática" - em alusão ao cientificismo que estava na base da sociologia como moderna ciência, à maneira de Durkheim, ou da sociologia norte-americana da primeira metade do século XX. Bastide colocou-se em defesa do diálogo sociológico com a literatura, justamente o que praticava Freyre, seja como leitor de literatura (inclusive a de viagem), seja 
como "escritor" - palavra que ele preferia a sociólogo -, ao praticar um texto que se pretendia literário, sem deixar de empregar a pesquisa de campo.

Mestiça cientificidade concentra atenção noutro lugar, ao refletir sobre o modo freyriano de escrever e de pensar, ou, para ser mais preciso, sobre seu modelo de cognição, muito ao gosto dos "três leitores franceses" em questão. O texto, vazado na forma de ensaio, implica um manejo poético da língua, que servia antes para engendrar imagens, às vezes impressionistas, do que para lançar mão de frios conceitos, cientificamente controlados. Braudel não se cansava de afirmar que o texto de Freyre "sabe ver e fazer ver" e, por fim, "seduzir" o leitor.

O modo freyriano de escrever, nota Antônio Dimas no prefácio do livro em questão, deixa "ao leitor parte da tarefa. Ao narrador não compete a totalidade do fato narrado, nem o papel de mero informante. Ele é simples (?!) intermediário, que instiga as questões, que alicia o leitor" (Venancio; Furtado, 2020, p. 22). A “mestiça cientificidade" impressa no título é uma alusão ao texto de Freyre, que se arma contra a tradição cientificista e objetivista, pois é aberto, observa Lucien Febvre, ao emocional, ao incerto, à curiosidade, à vida privada, à sexualidade, à comida e aos modos de ser e de estar, ou ainda aos detalhes insignificantes que, no conjunto, produzem imagens mentais que aliciam os leitores, inclusive os "três leitores franceses de Gilberto Freyre". Nas palavras de Venancio e Furtado:

Contra o purismo científico e a ortodoxia sociológica, que pareciam fazer vista grossa para o caráter complementar da contribuição de vários ensaístas - fossem eles escritores de romances, críticos, filósofos ou historiadores -, o autor de Maîtres et Esclaves [o título francês de Casa-grande] propunha, de certa maneira, o que se pode-se considerar de uma mestiça cientificidade, ainda que não nomeada dessa forma (Venancio; Furtado, 2020, p. 37).

Como se pode ver, Mestiça Cientificidade, ao discutir a recepção francesa de Casa-grande, pretende pensar o ensaio, um gênero que propiciava uma reflexão simultaneamente subjetiva e intuitiva, sem abrir mão da crítica, do arquivo e da erudição, enfim, um modo de pensar e escrever que, nos anos de 1950, estava sob intensa crítica de Florestan Fernandes e de seu grupo.

Fernand Braudel escreve sobre a obra de Freyre em 1943, ao publicar, na revista dos Annales, longo texto em que analisa Casa-grande \& Senzala (1933), Sobrados e Mucambos (1936) e Nordeste (1937) (Braudel, 1943), onde também cita Capistrano de Abreu, Roberto Simonsen, Pedro Calmon, Afonso de Taunay 
e Caio Prado Junior. Venancio e Furtado enfatizam o apreço do historiador francês pelo texto de Freyre, que teria a capacidade de levar "o leitor a acompanhá-lo, inclusive, até o Egito e Portugal antigos ou ao Sul dos Estados Unidos da América, esse deep South no qual Freyre gostava de se demorar, trazendo ricas informações e pensamento" (Venancio; Furtado, 2020, p. 50).

Braudel tinha franca simpatia pela interdisciplinaridade de Freyre e pelo tom literário de sua prosa, sem deixar de considerá-lo um historiador, "no sentido mesmo que a palavra vinha adquirindo para os leitores dos Annales", pois capaz de transitar "por vários domínios do saber, alimentado pelos ingredientes do salutar campo mais nitidamente literário" (Venancio; Furtado, 2020, p. 52), em explícita e positiva referência ao ensaio, marcado por lembranças pessoais, proximidade subjetiva - inclusive sua própria genealogia: "tão cheia de história, poesia e inteligência era a sua escrita, continuava ele [Braudel], que não seria mais possível falar sobre o Brasil e a América, inclusive, sem que os termos utilizados pelo intelectual pernambucano viessem aos lábios (Venancio; Furtado, 2020, p. 66).”.

É preciso lembrar que o Braudel de 1943, que escrevia sobre Freyre, ainda não era o reputado professor da Sorbonne, nem o consagrado autor de $\mathrm{OMe}$ diterrâneo e o Mundo Mediterrâneo na Época de Filipe II, publicado em 1949. Braudel escreveu (sobre Freyre e grande parte do Mediterrâneo) enquanto era um prisioneiro de guerra. Ele havia caído em 1940, como caíra a Linha Maginot e toda a França, em mãos inimigas. A lembrança "feliz de Brasil" certamente ampliava a simpatia tanto pelo país supostamente não racista, ou pouco racista - o qual, aliás, acabava de entrar na Guerra contra a Alemanha nazista quanto por Gilberto Freyre, seu grande tradutor. As circunstâncias pessoais e intelectuais de Braudel - de curta, mas intensa vivência brasileira - poderiam ter sido mais bem exploradas pelos autores, pois não há dúvida que a experiência humana de um leitor afeta as condições da leitura.

A longa apreciação de Braudel não foi apenas positiva. Uma das críticas à obra de Freyre está no emprego do modelo das casas grandes e do Nordeste açucareiro para explicar todo o processo histórico brasileiro. A questão, notam Venancio e Furtado, já havia sido apontada por Sérgio Milliet em resenha de Nordeste, na revista do IHGSP, em 1937: "Braudel parecia endossar a crítica dos intelectuais paulistas à obra de Gilberto Freyre, marcada pelo esforço de pensar menos o Brasil e mais o Nordeste, em particular Pernambuco" (Venancio; Furtado, 2020, p. 66).

Nordeste, um ensaio publicado em 1937, carrega as marcas de Casa-grande, com seus "equilíbrios de antagonismos", mas o livro é diferente, a começar por 
centrar a observação nos desequilíbrios ambientais. Não é apenas a ecologia, mas também as marcas da geografia, vivas em Nordeste, que o diferenciam de Casa-grande. Freyre conhecera e havia incorporado a geografia de Vidal de la Blache; Braudel, um autor sensível ao tema, percebe a inovação em Nordeste. Venancio e Furtado pouco exploram essa diferença. Por outro lado, insistem com acerto no argumento de Braudel quanto à especificidade de São Paulo colonial, uma formação histórica marcada pelo movimento, ao contrário do mundo dos engenhos nordestinos, mais estáticos e pesadamente plantados na terra. A mobilidade da colonização paulista, tema que Sérgio Buarque também exploraria em textos que compuseram Caminhos Fronteiras, não escapou de Braudel. A passagem do historiador francês pela USP e a convivência com a intelectualidade paulista poderia ter recebido mais atenção em Mestiça Cientificidade.

Entre os leitores franceses de Freyre, ninguém teve mais funda vivência brasileira, tanto em sentido intelectual quanto pessoal, que Roger Bastide. Ele viveu no Brasil entre 1938 e 1951, antes de se tornar professor da École Pratique des Hautes Études (EPHE, 6 section). Como já mencionado, foi justamente Bastide quem traduziu Casa-grande à língua francesa, pela prestigiosa editora Gallimard. Ao que tudo indica, foi o próprio Freyre quem indicou Bastide para traduzir o livro. Aliás, Gilberto Freyre dedicou Região e Tradição, livro de 1941, pela José Olympio, a três sociólogos franceses com atuação em São Paulo: Paul Arbousse-Bastide, Pierre Monbeig e Roger Bastide, "como testemunho do seu apreço pelas 'coisas da França'”.

Roger Bastide foi um intelectual próximo dos temas culturais e da literatura, ou do que se poderia chamar de "sociologia proustiana", como Freyre se referia à sua própria sociologia. Bastide elogiava o texto de Freyre, considerando-o ensaístico, mas em sentido positivo. Chega a afirmar que o texto freyreano é "sensual", capaz de contemplar a vida privada, a comida, a natureza, os animais, as miudezas que iluminam o todo, além das observações metafóricas. Tanto Freyre como Bastide se preocupavam com a narrativa, ambos admiradores de Marcel Proust. Embora Bastide tenha uma formação diferente de Braudel, ambos simpatizam com o que poderíamos chamar de tom literário contido na obra de Freyre.

Ademais, tanto Freyre quanto Bastide se interessam pela mestiçagem enquanto experiência histórica e antropológica, mas de pontos de vista diferentes. Freyre pensa, nas palavras de Bastide, "do ponto de vista da civilização brasileira", enquanto este próprio atenta às "civilizações africanas" (Venancio; Furtado, 2020, p. 73). Todavia, as diferenças não minimizam o profundo interesse de Bastide por Freyre. Devemos lembrar que, na década de 1950, o tema da 
“interpenetração das civilizações" estava em voga em uma Europa ainda traumatizada pela experiência trágica do nazifascismo e da Segunda Guerra Mundial; uma Europa que acabaria por animar projetos de integração cultural entre diferentes países e regiões (que, no limite, geraram a União Europeia).

Nesse contexto, a leitura de Casa-grande e a ideia (freyriana, mas não apenas) de um Brasil como alternativa não-racista ao mundo e laboratório de convivência racial era tese que, à época, gozava de certa respeitabilidade intelectual dentro e fora do país. Convém observar que, justamente a partir da década de 1950, o discurso racial de Freyre passou a ser fortemente questionado, sobretudo por autores mais jovens, sensíveis à politização da raça que marcou o pós-guerra. No Brasil, a linguagem de Freyre passou a ser criticada por seu caráter ensaístico, cuja forma narrativa expressaria a suposta ausência de cientificidade que, nas palavras da citada Simone Meucci, estaria "fora dos padrões discursivos sociologicamente legítimos"” (Venancio; Furtado, 2020, p. 83). "Mais artístico", o ensaísmo não é necessariamente "menos científico"1, embora no Brasil dos anos 50 - momento em que a especialização universitária das ciências sociais se aprofundava - não faltasse quem considerasse a obra de Freyre (e seu ensaísmo) como subjetivos e carentes de base documental.

Os autores de Mestiça Cientificidade observam que Freyre defendeu o ensaísmo usando como argumento o sucesso no exterior, em especial, das traduções em inglês e em francês, bem como a calorosa acolhida por intelectuais do porte de Fernand Braudel, Roger Bastide e Lucien Febvre. Nota-se que, no Brasil dos anos 50, vivia-se a profissionalização dos historiadores e sociólogos, com o enraizamento das universidades. Freyre recusou-se a seguir essa via, apostando no jornalismo - e na continuidade do ensaísmo, linguagem mais ajustada à imprensa. Convém lembrar que Gilberto Freyre escreveu, na Revista O Cruzeiro, uma coluna semanal intitulada Pessoas, Coisas e Animais, publicada entre 1948 e 1967. O Cruzeiro era a principal revista semanal do país. Ganhar a vida na imprensa e não na universidade têm implicações que a crítica freyriana ainda está por elucidar.

Freyre não gostou da tradução de Bastide para Casa Grande \& Senzala. Não há espaço nos limites dessa resenha para se discutir a questão, mas vale escutar as observações de Venancio e Furtado: "É possível que o desgosto de Freyre se baseasse ainda no seguinte aspecto: ao adequar o texto da língua francesa, Bastide teria atuado como intérprete da obra, evidenciando uma nova escrita igualmente de caráter autoral" (Venancio; Furtado, 2020, p. 92). Freyre, famoso pela vaidade que ele mesmo admitia, talvez preferisse um tradutor "invisível", que não ferisse nem competisse com o texto de um autor 
preocupado com a escrita autoral, que buscava articular conteúdos científicos e poéticos. Eis aqui a mestiça cientificidade de Freyre.

Lucien Febvre atuou fortemente nas negociações que culminaram na tradução de Casa-grande em língua francesa, que recebeu o título de Maîtres et Esclaves, cujo prefácio coube ao próprio Febvre, emprestando-lhe autoridade e credibilidade.

Febvre também leu Casa-grande \& Senzala como um ensaio, ou seja, uma construção intelectual que articula a erudição e os conceitos da moderna ciência social, mas permeados por certa introspecção autoral, em que o texto não funciona como um mero transmissor de informações, mas é também uma maquinaria literária que comunica, pensa e ilumina. Maîtres et Esclaves é apresentado como panorama sobre o passado, em diálogo com o presente e o futuro. Trataria "enfim, de um escritor que considerou nato", "lúcido", portador de "narrativa sedutora". Dos três leitores franceses de Freyre aqui tratados, Febvre é aquele que teve menos intimidade com o Brasil. No entanto, como Braudel, era um historiador sensível à geografia, acalentando interesse pela "imensidão do Brasil e o problema maravilhoso que isso, por si só, representava”. Na condição de leitor,

Alertava que se enganavam aqueles que, tendo feito o percurso do Rio de Janeiro e de São Paulo, julgavam conhecer esta grande nação. Na sequência, Lucien Febvre registrava uma série de impressões pessoais sobre o passado e o presente não só dessas regiões como também de Santos e ainda de Belo Horizonte, Sabará, Ouro Preto, Tiradentes, destacando seus antigos universos bem vivos e salvos em museus, igrejas e/ou passos municipais (Venancio; Furtado, 2020, p. 106).

Febvre se entusiasmava com a mestiçagem e a pluralidade brasileiras, embora argumentava que faltavam indígenas em Casa-grande. No entanto, bem ao gosto de Freyre, associava mestiçagem à sexualidade. Mesmo sem conhecer os meandros do debate brasileiro, a recepção de Casa-grande por Lucien Febvre se alimenta, de acordo com Venâncio e Furtado, dos "diálogos com agentes e trânsitos em instituições que estavam a par dessas pautas o tornavam integrante ativo das redes nas quais os assuntos em destaque emergiam. Logo, habilitado a falar deles" (Venancio; Furtado, 2020, pp. 109-110). Febvre tinha uma adesão emocional aos códigos interpretativos de Freyre - mais intensamente do que Braudel apresentava no texto de 1943 -, saudando a "coragem" do ensaísta brasileiro, o qual, na década de 1930, tocara, de modo particularmente interdisciplinar, em temas como o racismo, a sexualidade e a presença negra 
impostos pela escravidão africana. É compreensível o entusiasmo de Febvre em relação a Freyre, que exitosamente abordava o cotidiano e a vida privada, muito longe da história política que Febvre e Braudel combatiam no âmbito da renovação da historiografia francesa em curso nos anos 50.

Por que ler Mestiça cientificidade: três leitores franceses de Gilberto Freyre e a sua máxima consagração no exterior, de Giselle Venancio e André Furtado? Primeiro, porque a obra joga luz na recepção internacional de um dos mais importantes autores brasileiros do século XX, invertendo o fluxo das ideias - da América do Sul para a Europa, do Brasil para a França -, e não o contrário, como é comum em nossa tradição colonial. Em segundo lugar, porque politiza as condições de leitura, circulação e recepção da produção intelectual. Sob os escombros da guerra, Gilberto Freyre foi lido como um "discurso de 'esperança pacifista que buscava promover, ao priorizar o caráter positivo da mestiçagem e da interdependência dos homens, a paz almejada pelas sociedades da Europa"' (Venancio; Furtado, 2020, p. 120).

O mesmo Gilberto Freyre publicaria Aventura e Rotina e Um Brasileiro em Terras Portuguesas em 1953, ano seguinte à publicação de Maîtres et Esclaves (1952). Fora lido por intelectuais africanos, como Amílcar Cabral, Mário de Andrade (o angolano) ou Agostinho Neto; nos mesmos anos de 1950, o significado político da leitura seria outro, afinal, como nos lembra Michel de Certeau, a operação do leitor é uma espécie de produção própria. O leitor "não toma nem o lugar do autor nem um lugar de autor. Inventa nos textos a 'intenção’ deles. Combina os seus fragmentos e cria algo não-sabido no espaço organizado por sua capacidade de permitir uma pluralidade indefinida de significações" (De Certeau, 1994, p. 262).

O livro de Giselle Venancio e André Furtado circunscreve a pesquisa e a recepção francesa da obra de Freyre, e o faz com notável qualidade. Serve ao pesquisador de história intelectual, aos especialistas em Gilberto Freyre e aos jovens estudantes interessados no tema. Não menos meritório é o papel das editoras das universidades públicas, como é o caso da Eduff, ao oferecer ao público pesquisas atualizadas, nascidas no interior de programas de pós-graduação que, apesar de tantos serviços prestados ao país, estão, nestes tristes dias, sob a ameaça do obscurantismo. 


\section{REFERÊNCIAS}

BOXER, Charles R. Race Relations in the Portuguese Colonial Empire, 1415-1825. London: Clarendon Press, 1963.

BOXER, Charles R. Relações raciais no império colonial português, 1415-1825. Tradução de Elice Munerato. Rio de Janeiro: Edições Tempo Brasileiro, 1967.

BRAUDEL, Fernand. À travers un continent d'histoire: le Brésil et l'oeuvre de Gilberto Freyre. Mélanges d'histoire sociale, Paris, v. 4, pp. 3-20, 1943.

CESAIRE, Aimé. Discours sur le colonialisme. Paris: Réclame, 1950.

DE CERTEAU, Michel. A invenção do cotidiano: Artes de fazer. Petrópolis: Vozes, 1994.

FANON, Frantz. Peau noire, masques blancs. Paris: Les Éditions du Seuil, 1952.

FANON, Frantz. Les Damnés de la Terre. Paris: Éditions Maspero, 1961.

FREYRE, Gilberto. The Masters and the Slaves: A Study in the Development of Brazilian Civilization. New York: Alfred, A. Knopf, 1946.

FREYRE, Gilberto. The Masters and the Slaves: A Study in the Development of Brazilian civilization. London: Knopf, 1947.

FREYRE, Gilberto. Casa-grande \& Senzala. Rio de Janeiro: Editora Schmidt. 2a Ed, 1936 [1933].

FREYRE, Gilberto. Maîtres et esclaves. Trad. du portugais (Brésil) par Roger Bastide. Préface de Lucien Febvre. Paris: Gallimard, 1952.

LÉVI-STRAUSS, Claude. Race et histoire. Paris: Unesco, 1952.

LÉVI-STRAUSS, Claude. Tristes tropiques. Paris: Plon, 1955.

LEIRIS, Michel. Race et civilisation. La question raciale devant la science moderne. Paris: Unesco, 1951.

VENANCIO, Giselle Martins; FURTADO, André. Mestiça cientificidade: três leitores franceses de Gilberto Freyre e a sua máxima consagração no exterior. Niterói: Eduff, 2020.

VENANCIO, Giselle; WEGNER, Robert. Uma vez mais, Sérgio e Gilberto. Debates sobre o ensaísmo no suplemento literário do Diário de Notícias (1948-1953). Varia Historia, Belo Horizonte, v. 34, n. 66, pp. 729-762, 2018.

\section{NOTA}

${ }^{1} \mathrm{O}$ assunto reaparece em Venancio e Wegner, 2018.

Resenha submetida em 18 de agosto de 2021.

Aprovada em 16 de novembro de 2021. 